\title{
Comparison of Prevalence of Diabetes Mellitus, Medical Expenses, Inpatient, Emergency and Outpatient According to the Level of Physical Activity of Korean Adults: A Cross-Sectional Study
}

\section{Byung Kun Lee ${ }^{1 *}$}

${ }^{1}$ Department of Lifetime Sports and Leisure, SangMyung University

Received: June 22, 2018

Accepted: July 24, 2019

Published online: July 30, 2019

Keywords:

Hospitalization

Korean adults

Medical expenses

Physical activity

Prevalence of diabetes mellitus
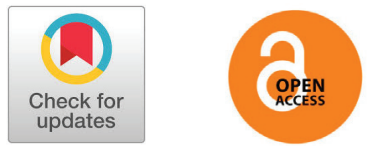

\section{ABSTRACT}

OBJECTIVES The purpose of this paper is to analyze the differences in the prevalence of diabetes mellitus, in relation to the physical activity grade and to compare differences in, personal medical expenses, the days of hospitalization, inpatient, outpatient and emergency.

METHODS The medical panel data of Korea used in 2016, with a total of 13,523 adults and 1,404 diabetes mellitus patients. Physical activity level measured with IPAQ questionnaire, and displayed as MET-minutes per week. The days of hospitalization, personal medical expenses, using of inpatient, outpatient and emergency investigated, and frequency analysis, logistic regression, ANOVA, and Chi-square performed. RESULTS The prevalence of diabetes mellitus based on inactive group was reduced both minimally active group (odds ratio $[O R]=0.81)$ and active group $(O R=0.73, p<.01)$. The personal medical expenses $I(p<.05)$ and II $(p<.01)$ were all significantly different among each physical activities group. Medical expenses have increased by 33.3 35.1\% in minimally active group compared with active group, while inactive groups have increased rapidly by 58.8 65.6\%. There were significant differences in inpatient and emergency using depend on the level of physical activity.

CONCLUSIONS The SEI could provide a relative evaluation of jumping performance depending on physical resources without consideration of physique.

(c) The Asian Society of Kinesiology and the Korean Academy of Kinesiology
서론

신체활동 부족은 공중 보건의 측면에서 중요한 문제 로 알려져 있다. 신체활동이 체력과 건강의 측면에서 유 익한 효과가 보고되고 있음에도 불구하고 $[1,2]$, 세계 인 구의 $1 / 3$ 이 권장 최소 활동량에 도달하지 못하고 있다고 보고되고 있다 [3]. 세계보건기구(WHO)는 신체활동 부족 은 전 세계 10 대 사망원인 요인 중 하나이며, 심혈관계질 환, 암, 당뇨병과 같은 비감염성질환의 주요 위험요인이 라고 하고 있다 [4]. 한국의료패널에서도 7대 만성 질환인

*Correspondence: Byung Kun Lee, Department of Lifetime Sports and Leisure SangMyung University, 31 Sangmyungdae-gil, Dongnam-gu, Cheonan, ChungNam, South Korea; Tel: +41-550-5347; Fax: +41-550-5339; E-mail: bklee@smu.ac.kr
고혈압, 당뇨병, 고지혈증, 관절병증, 결핵, 허혈성 심장질 환, 뇌혈관 질환을 중심으로 조사해 오고 있다.

미국의 경우 당뇨 유병률은 9.3\%이고 [5] 심장병, 암, 호흡기질환, 비의도성 사고, 알츠하이머와 함께 7 대 사망 원인으로 보고되고 있으며 [6], 우리 나라의 경우 2017년 당뇨 유병률은 $10.4 \%$ 로 보고되고 있다[7]. 당뇨는 고혈압, 심장질환, 안과 질환, 신장 질환, 호흡순환계 질환 등에도 관련이 높은 것으로 보고되고 있다[5]. 당뇨 유병률은 증 가하여 2,050년에는 $25 ~ 33 \%$ 에 이를 것으로 예측되고 있 다 [8]. 규칙적인 신체활동은 고혈압, 당뇨병, 심장질환 사 망 위험률, 직장암 등의 감소, 체중조절, 건강한 뼈와 관절 유지, 심리학적 안녕 유지 등에 긍정적인 효과가 있다고 


\section{보고되고 있다 $[9,10]$.}

생활 양식 개선에 참여한 사람은 체중 감소, 혈당 조절, 혈압 삶의 질, 당뇨 동반 질환 등의 개선 및 총 질병관리 비 용 감소 등이 나타난다고 보고되고 있다 [11-13]. 체중 감 소가 없는 경우에 도 과체중의 당뇨 환자에 게서 규칙적인 신체활동은 혈압, 지질 수준 및 글루코스 조절 이상의 개 선이 나타날 수도 있다고 보고되고 있다 [14]. Cornelissen et al. [15]은 조깅과 사이클과 같은 규칙적인 유산소 운동 이 안정시 혈압을 $3.5 / 2.5 \mathrm{mmHg}$ 정도 저하시키는 작용을 한다고 하였다.

신체활동과 질병 및 의료이용의 관계를 분석한 연구를 살펴보면, 신체활동 정도가 입원빈도와 입원기간과 유의 한 상관관계가 보고되고 있으며 [16], Moraes [10] 운동은 순환계 심혈관질환을 호전시키는데 도움이 된다고 하였 다. Lee [17]은 2015년 국민건강영양조사 자료를 이용하여 악력이 높을수록 고강도 운동, 근력운동, 유연성 운동에 더 많이 참여하고 있었으며, 악력이 높을수록 고혈압의 유병 률이 낮게 나타났다고 하였다. 신체활동을 하지 않는 사 람이 적극적인 신체활동을 하는 사람보다 입원진료 이용 률이 약 $38 \%$ 더 높았다고 보고되고 있다 [18].

하지만 한국인을 대상으로 대표성 있는 최신 자료를 활용하여 당뇨 유병률과 신체활동 수준 관계에 연구는 미 미한 편이다. 의료이용과 의료비용에 대한 조사 내용을 다양하게 구성된 한국의료패널 자료를 이용하여 당뇨 질 환자의 의료비용, 입원일수, 입원, 응급실 이용 여부 등의 차이에 대해 종합적으로 비교-분석한 연구는 미미한 실 정이었다.

본 연구의 목적은 최신 공개 자료인 2016년 한국의료 패널 중에서 성인을 대상으로 하여 신체활동 등급에 따른 당뇨 유병률의 차이를 비교하고, 당뇨 환자의 신체활동 등 급에 따른 연간 의료비, 연간 입원일수, 입원, 외래 및 응급 실 이용 여부의 차이를 분석하는데 있다.

\section{연구방법}

\section{분석자료 및 연구대상}

본 연구에서는 현재까지 제공된 가장 최신 자료인 2016 한국의료패널 원시자료를 이용하였다. 한국의료패널은 정부승인 지정통계조사이며 승인번호 92012호(2007년) 이다. 2005년 인구주택총조사 자료를 추출틀로 하고 있으 며, 2008년부터 매년 건강행태 및 수준, 보건의료이용 상황
과 의료비 등에 관한 다양한 자료를 조사하고 있다. 대상 선정은 표본조사구를 집락 추출과 표본가구를 추출하는 2 단계 확률비례 층화집락추출 방법으로 하였다. 표본 조 사구는 약 350 개이며, 2008 년에는 7,866 가구를 조사하였 고, 일부 누락 가구가 발생하여 2013년에 2,222가구(6,454 가구원)을 신규로 추가하였다. 본 연구의 대상은 2016년 데이터 중 성인 남녀 총 13,523 명이었고, 이 중 의사에 게서 당뇨로 진단받은 환자는 1,404 명이었다. 분석 자료는 응답 자 고유의 가구와 가구원 $\mathrm{ID}$ 를 이용하여 자료를 통합하였 다. (Table 1)은 연구 대상자의 인구실태, 체격자료 및 건강 과 질병 행태의 자료이다.

\begin{tabular}{|c|c|c|c|c|}
\hline Variables & Categories & $\mathbf{N}$ & $\%$ & Mean \pm SD \\
\hline \multicolumn{5}{|c|}{ Demographics } \\
\hline \multirow[t]{3}{*}{ Sex } & Male & 6,028 & 44.6 & \\
\hline & Female & 7,086 & 52.4 & \\
\hline & Missing values & 409 & 3.0 & \\
\hline \multicolumn{2}{|l|}{ Age } & & & $53.5 \pm 17.3$ \\
\hline \multicolumn{5}{|c|}{ Physical measurements } \\
\hline \multicolumn{2}{|l|}{ Height(cm) } & & & $163.6 \pm 9.0$ \\
\hline \multicolumn{2}{|l|}{ Weight(kg) } & & & $62.5 \pm 11.4$ \\
\hline \multicolumn{2}{|c|}{ Body mass index } & & & $23.2 \pm 3.1$ \\
\hline \multicolumn{5}{|c|}{ Health habit and disease } \\
\hline \multirow[t]{2}{*}{ Smoking } & Smoker & 5,017 & 37.1 & \\
\hline & Nonsmoker & 8,506 & 62.9 & \\
\hline \multirow[t]{4}{*}{ Drinking } & Nondrinker & 3,620 & 26.8 & \\
\hline & Below 1 time per month & 3,061 & 22.6 & \\
\hline & 1 to 3 times per month & 3,062 & 22.6 & \\
\hline & Above 1 time per week & 3,780 & 28.0 & \\
\hline \multirow[t]{2}{*}{ Disease } & Diabetes Mellitus & 1,404 & 10.4 & \\
\hline & Non-Diabetes Mellitus & 12,119 & 89.6 & \\
\hline
\end{tabular}

\section{변수의 정의 및 측정도구}

신체활동은 IPAQ(International Physical Activity Questionnaire)의 단문형을 이용하여 측정하였으며, 단문 형은 7 개의 문항으로 국가 혹은 지역관리 시스템에 적합 한 형태이며, 장문형은 27 개의 문항으로 심도 있는 자료 수집에 적합한 형태이다 [19]. IPAQ 단문형은 최근 7일 동 안 10 분 이상 참여한 걷기, 중등도 활동 및 격렬한 신체활 동의 주당 일수와 평균 시간(하루당 시간과 분)에 대한 설 문이다. 신체활동량은 단문형 설문 자료를 이용하여 주당 
$\mathrm{MET}$ (metabolic equivalent)-분으로 환산하였다. 걷기의 운 동강도는 $3.3 \mathrm{MET}$, 중등도 활동의 강도는 $4.0 \mathrm{MET}$, 격렬한 활동의 강도는 $8.0 \mathrm{MET}$ 로 설정하였다. 비활동(inactive) 집 단은 $600 \mathrm{MET}$-분 미만, 최소활동(minimally active) 집단은 600 3,000MET-분, 고활동 (active) 집단은 주당 3,000MET분 이상으로 분류하였다 [19].

연간 개인의료비I은 입원, 외래 및 응급의료비 및 처방 약값을 대상자가 수납한 금액을 합한 것이며, 연간 개인의 료비II는 연간 개인의료비I에 입원, 외래 및 응급교통비와 입원간병비를 합한 금액이다. 의료비 금액은 원(Won) 단 위로 표시하였으며, 달러(\$)로 환산할 때는 $\$ 1$ 를 1,100 으로 하여 표시하였다. 연간 입원일수는 1 년 동안 병원에 입원한 전체 일수이다. 입원과 외래 및 응급실 이용 여부 도 함께 조사하였다.

\section{자료처리방법}

자료처리에 는 IBM SPSS Statistics 23.0을 사용하였고, 가구원 일반사항, 당뇨 진단 여부 판정, 신체활동 산출 및 등급 판정, 연간 입원일수, 연간 개인의료비 및 연간 개인 의료비II를 분석하였다. 자료 중 성별과 건강습관 및 질병 에 대하여 빈도분석을 실시하였고, 연령과 체격요인은 기 술분석을 실시하였다. BMI(body mass index), 흡연과 음주 를 공변량으로 통제하고 신체활동 집단에 따른 당뇨 유병 률의 차이를 비교하기 위하여 로지스틱 회귀분석(logistic regression)을 실시하였다. BMI는 원수치를 입력하였고, 흡 연은 흡연여부로 구분하였고, 음주는 음주 빈도를 기준으 로 하여 평생 금주, 최근 1 년간 금주, 월 1회 미만, 월 1회, 월2 3회, 주 1회, 주 2 3회, 거의 매일로 구분하였다. 당뇨 환자의 신체활동 집단에 따른 연간 개인의료비와 월평균 약값 및 입원일수를 비교하기 위하여 변량분석(analysis of variance: ANOVA)을 실시하고 Tukey 방법으로 사후검 증을 실시하였다. 당뇨 환자의 신체활동 집단에 따른 입 원 여부, 응급실 이용 및 외래 여부의 차이를 알아보기 위 하여 교차분석을 실시하였다. 본 연구는 횡 단연구 자료 이므로 신체활동에 따른 의료비, 입원일수, 입원과 응급 실 이용 여부 등의 차이가 나타나는 인과관계를 설명하는 것은 아니라고 하겠다. 통계적 유의수준 $\alpha=.05$ 로 하였다.

\section{결과}

(Table 2)는 신체활동 집단에 따른 당뇨 유병률의 차이 를 알아보기 위하여 logistic 회 귀분석을 실시한 결과이다. 비활동 집단의 고혈압 유병률을 1.00 으로 하였을 경우 최 소활동 집단의 유병률의 $\mathrm{OR}$ 이 $0.81(95 \% \mathrm{CI}=0.65-1.02)$ 로 $19.0 \%$ 감소하였고 $(\mathrm{p}=.072)$, 고활동 집단의 유병률의 $\mathrm{OR}$ 이 $0.73(95 \% \mathrm{CI}=0.58-0.91)$ 로 $27.0 \%(\mathrm{p}<.01)$ 감소하는 것으로 나타났다. 당뇨 유병률을 BMI, 흡연과 음주 변수를 공변 량으로 분석한 결과, 최소활동 집단의 $\mathrm{OR}$ 은 $0.82(95 \% \mathrm{CI}=$ $0.66-1.03)$ 로 $18.0 \%$ 감소하였고 $(\mathrm{p}=0.081)$, 고활동 집단의 유 병률의 $\mathrm{OR}$ 이 $0.76(95 \% \mathrm{CI}=0.61-0.96)$ 으로 $34.0 \%(\mathrm{p}<.05)$ 감 소하는 것으로 나타났다. 즉, 신체활동 수준이 상승할수록 당뇨 유병률이 $19.0 \%$ 에서 $27.0 \%$ 감소하며, 공변량을 통제 한 경우에는 $18.0 \%$ 에서 $34.0 \%$ 감소하는 것으로 나타났다.

(Table 3)은 당뇨 환자의 신체활동 집단에 따른 연간 개인의료비와 연간 입원일수를 비교하기 위하여 변량 분석을 실시한 결과이다. 당뇨 환자의, 연간 개인의료비 $\mathrm{I}(\mathrm{p}<.01)$. 및 연간 개인의료비 $\mathrm{II}(\mathrm{p}<.01)$ 는 모두 신체활동 집 단간에 유의한 차이가 나타났다. 연간 개인의료비I은 응 급, 외래 및 입원의료비 및 처방약값을 합한 비용이며, 연 간 개인의료비II는 연간 개인의료비I에 입원, 응급 및 외 래교통비와 입원간병비를 합한 것이다. 연간 개인의료비

\begin{tabular}{|c|c|c|c|c|c|}
\hline \multirow{2}{*}{ Physical activity grade } & \multirow{2}{*}{$N(\%)$} & \multicolumn{4}{|c|}{ Diabetes Mellitus } \\
\hline & & Unadjusted OR (95\% Cl) & $\mathbf{p}$ & Adjusted OR (95\% Cl) & $\mathbf{p}$ \\
\hline $1^{\text {st }}$ grade inactive & $6330(46.8)$ & 1.00 & & 1.00 & \\
\hline $2^{\text {nd }}$ grade minimally active & $6049(44.7)$ & $\begin{array}{c}0.81 \\
(0.65 \sim 1.02)\end{array}$ & 0.072 & $\begin{array}{c}0.82 \\
(0.68 \sim 1.03)\end{array}$ & 0.081 \\
\hline $3^{\text {rd }}$ grade active & $1143(8.5)$ & $\begin{array}{c}0.73 \\
(0.58 \sim 0.91)\end{array}$ & $0.005^{* *}$ & $\begin{array}{c}0.76 \\
(0.61 \sim 0.96)\end{array}$ & $0.018 *$ \\
\hline
\end{tabular}


Table 3. Days of hospitalization, drug expenses for hypertension, and personal medical expenses according to physical activity grade of Diabetes Mellitus patients

\begin{tabular}{|c|c|c|c|c|}
\hline Contents & $\begin{array}{l}\text { inactive grade } \\
(\mathrm{N}=702,54.2 \%)\end{array}$ & $\begin{array}{l}\text { minimally active grade }(\mathrm{N}=607 \text {, } \\
39.2 \%)\end{array}$ & $\begin{array}{l}\text { active grade } \\
(\mathrm{N}=95,6.6 \%)\end{array}$ & $\mathbf{p}$ \\
\hline $\begin{array}{l}\text { Annual personal medical } \\
\text { expenses }\left.\right|^{1)}\end{array}$ & $\begin{array}{l}\$ 1,527,112 \pm 2,416,028 \\
\$ 1,388.3 \pm 2,196.4 \\
(158.8 \%)^{b}\end{array}$ & $\begin{array}{l}\$ 1,281,236 \pm 1,650,586 \\
\$ 1,1164.8 \pm 1,500.5 \\
(133.3 \%)^{a b}\end{array}$ & $\begin{array}{l}\$ 961,462 \pm 1,828,570 \\
\$ 874.1 \pm 1662.3 \\
(100.0 \%)^{a}\end{array}$ & $.013 *$ \\
\hline $\begin{array}{l}\text { Annual personal medical } \\
\text { expenses II }{ }^{2)}\end{array}$ & $\begin{array}{l}\$ 1,613,752 \pm 2,691,721 \\
\$ 1,467.0 \pm 2,447.0 \\
(165.6 \%)^{b}\end{array}$ & $\begin{array}{l}\$ 1,316,160 \pm 1,698,351 \\
\$ 1,196.5 \pm 1,544.0 \\
(135.1 \%)^{a b}\end{array}$ & $\begin{array}{l}\$ 974,406 \pm 1,832,655 \\
\$ 885.8 \pm 1,666.1 \\
(100.0 \%)^{a}\end{array}$ & $.007^{* *}$ \\
\hline $\begin{array}{l}\text { Annual days of } \\
\text { hospitalization }\end{array}$ & $\begin{array}{l}13.7 \pm 22.8 \\
(150.5 \%) \\
(\mathrm{N}=155)\end{array}$ & $\begin{array}{l}10.1 \pm 15.2 \\
(111.0 \%) \\
(\mathrm{N}=84)\end{array}$ & $\begin{array}{l}9.1 \pm 10.4 \\
(100.0 \%) \\
(\mathrm{N}=7)\end{array}$ & .387 \\
\hline
\end{tabular}

1) Personal expenditure medical expenses I per year = emergency medical expenses + outpatient medical expenses + hospitalization medical expenses + inpatient drug expenses + emergency prescription drug expenses + outpatient drug expenses.

2) Personal expenditure medical expenses II per year = Personal expenditure medical expenses II + inpatient transportation cost + emergency transportation cost + inpatient nursing cost + outpatient transportation cost

W : Korea monetary unit(Won), \$1 = W1,100

${ }^{*} p<.05 ;{ }^{* *} p<.01$ significance level of ANOVA

$a, b, c$ : Each character means homogenesis group.

Table 4. Chi-square of inpatient and non-inpatient according to physical activity grade of Diabetes Mellitus patients

\begin{tabular}{|c|c|c|c|c|c|}
\hline & Contents & inactive grade & minimally active grade & active grade & total \\
\hline \multirow{4}{*}{ inpatient } & observation frequency & 193 & 106 & 10 & 309 \\
\hline & expected frequency & 154.5 & 133.6 & 20.9 & 309 \\
\hline & frequency percent(\%) ${ }^{\#}$ & 124.9 & 79.3 & 47.8 & \\
\hline & percent of hospital (\%) & 62.5 & 34.3 & 3.2 & 100.0 \\
\hline \multirow{4}{*}{$\begin{array}{l}\text { Non- } \\
\text { inpatient }\end{array}$} & observation frequency & 509 & 501 & 85 & 1095 \\
\hline & expected frequency & 547.5 & 473.4 & 74.1 & 1095 \\
\hline & frequency percent(\%) & 93.0 & 105.8 & 114.7 & \\
\hline & percent of hospital (\%) \# & 46.5 & 45.8 & 7.8 & 100.0 \\
\hline $\begin{array}{l}\text { total } \\
p=.00\end{array}$ & observation frequency & 702 & 607 & 95 & 1404 \\
\hline$* *$ & percent of hospital (\%) & 50.0 & 43.2 & 6.8 & 100.0 \\
\hline
\end{tabular}

I은 고활동 집단이 $\$ 961,462 \pm 1,828,570$ 이었으며, 최소활 동 집단은 $33.3 \%$, 비활동 집단은 $58.8 \%$ 증가하였고 3 집단 간에 유의한 차이가 나타났으며 $(\mathrm{p}<.05)$, 고활동과 최소활 동, 최소활동과 저활동 집단이 등질집단으로 구분되었다. 연간 개인의료비II는 고활동 집단이 $¥ 961,462 \pm 1,828,570$ 이었으며, 최소활동 집단은 $35.1 \%$, 비활동 집단은 $65.6 \%$ 증가하였고 3 집 단간에 모두 유의한 차이가 나타났으며 $(\mathrm{p}<.01)$, 고활동과 최소활동, 최소활동과 저활동 집단이 등질집단으로 구분되었다. 연간 입 원일수는 고활동 집단 이 $9.1 \pm 10.4$ 일이었으며, 최소활동 집단은 $10.1 \pm 15.2$ 일로 $11.1 \%$, 비활동 집단은 $13.7 \pm 22.8$ 일로 $50.5 \%$ 증가하였으나
3집단간에 유의한 차이가 나타나지 않았다. 고활동 집단을 기준으로 의료비와 입원일수를 비교해 보면 최소활동 집 단은 $11.1 \sim 35.1 \%$ 증가하였으나 비활동 집단은 50.5 65.6\% 증가하여 비활동 집단에서 더 급격하게 증가하는 것으로 나타났다.

(Table 4)는 신체활동 수준과 입원 여부에 대하여 교차 분석을 실시한 결과이다. 신체활동 수준에 따른 입원 여 부에는 유의한 차이가 나타났다 $(\mathrm{p}<.01)$. 고활동 집 단의 입 원 여부의 관측과 기대빈도 백분율은 $47.8 \%$ 이고 최고활 동 집단의 백분율은 $79.3 \%$ 로 적 게 나타났으며, 비활동 집 단의 백분율은 $124.9 \%$ 로 높게 나타났다. 즉, 고활동과 최 
Table 5. Chi-square of outpatient and non-outpatient according to physical activity grade of Diabetes Mellitus patients

\begin{tabular}{|c|c|c|c|c|c|}
\hline & Contents & inactive grade & minimally active grade & active grade & total \\
\hline \multirow{4}{*}{ outpatient } & observation frequency & 694 & 603 & 95 & 1392 \\
\hline & expected frequency & 696 & 601.8 & 94.2 & 1392 \\
\hline & frequency percent(\%) \# & 99.7 & 100.2 & 100.8 & \\
\hline & percent of hospital (\%) & 49.9 & 43.3 & 6.8 & 100.0 \\
\hline \multirow{4}{*}{$\begin{array}{l}\text { Non- } \\
\text { outpatient }\end{array}$} & observation frequency & 8 & 4 & 0 & 12 \\
\hline & expected frequency & 6 & 5.2 & 0.8 & 12 \\
\hline & frequency percent(\%) ${ }^{\#}$ & 133.3 & 76.9 & 0.0 & \\
\hline & percent of hospital (\%) & 66.7 & 33.3 & 0.0 & 100.0 \\
\hline \multirow{2}{*}{$\begin{array}{l}\text { total } \\
p=.41\end{array}$} & observation frequency & 702 & 607 & 95 & 1404 \\
\hline & percent of hospital (\%) & 50.0 & 43.2 & 6.8 & 100.0 \\
\hline
\end{tabular}

\# frequency percent $(\%)=[$ observation frequency / expected frequency $] * 100$

Table 6. Chi-square of emergency(EMC) using and non-using according to physical activity grade of Diabetes Mellitus patients

\begin{tabular}{|c|c|c|c|c|c|}
\hline & Contents & inactive grade & minimally active grade & active grade & total \\
\hline \multirow{4}{*}{ EMC using } & observation frequency & 106 & 48 & 13 & 167 \\
\hline & expected frequency & 83.5 & 72.2 & 11.3 & 167.0 \\
\hline & frequency percent(\%) \# & 126.9 & 66.5 & 115.0 & \\
\hline & percent of emergency(\%) & 63.5 & 28.7 & 7.8 & 100.0 \\
\hline \multirow{4}{*}{$\begin{array}{l}\text { EMC Non- } \\
\text { using }\end{array}$} & observation frequency & 596 & 559 & 82 & 1237 \\
\hline & expected frequency & 618.5 & 534.8 & 83.7 & 1237.0 \\
\hline & frequency percent(\%) \# & 96.4 & 104.5 & 98.0 & \\
\hline & percent of emergency(\%) & 48.2 & 45.2 & 6.6 & 100.0 \\
\hline $\begin{array}{l}\text { total } \\
p=.00\end{array}$ & observation frequency & 702 & 607 & 95 & 1404 \\
\hline ** & percent of emergency(\%) & 50.0 & 43.2 & 6.8 & 100.0 \\
\hline
\end{tabular}

소활동 집단의 입원 비율은 적게 나타났으나 비활동 집단 의 백분율은 더 높게 나타나 신체활동이 입원 비율 감소 에 긍정적인 작용을 하는 것으로 나타났다.

(Table 5)은 신체활동 수준과 외래 여부에 대하여 교차 분석을 실시한 결과이다. 신체활동 수준에 따른 외래 여 부에는 유의한 차이가 나타나지 않았다( $\mathrm{p}=.41) .3$ 집단 모 두 입원 여부의 관측과 기대빈도 백분율이 99.7 100.8로 유 사하게 나타났다. 즉, 입원 여부와는 달리, 신체활동 수준 에 따른 외래 여부에 대한 차이는 거의 나타나지 않았다.

(Table 6)는 신체활동 수준과 응급실 이용 여부에 대하 여 교차분석을 실시한 결과이다. 신체활동 수준에 따른 응 급 이용 여부에는 유의한 차이가 나타났다( $\mathrm{p}<.01)$. 최저활
동 집단의 입원 여부의 관측과 기대빈도 백분율은 $72.2 \%$ 이고, 비활동 집단의 백분율은 $126.9 \%$ 로 높게 나타났다. 즉, 최소활동 집단의 입 원 비율은 적게 나타났으나 비활 동 집단의 백분율은 더 높게 나타나 신체활동이 입원 비 율 감소에 긍정적인 작용을 하는 것으로 나타났다. 단 고 활동 집단의 입원 비율이 $115.0 \%$ 롷 높게 나타났지만, 사 례수가 13건 정도로 미미하였다.

\section{논의}

국내에서 건강관련 국가 자료는 국민건강영양조사와 한국의료패널 등이 있다. 국민건강영양조사는 같은 합동 
횡단면 자료이며 한국의료패널 동일한 개체를 반복적으 로 관찰하여 조사하는 자료이다. 본 연구에서는 한국의료 패널 자료를 이용하여 신체활동 수준에 따른 당뇨 유병률, 의료비, 입원일수, 그리고 입원, 외래 및 응급 이용 여부 등 의 차이를 분석하였다.

본 연구에서는 신체활동 수준을 측정하기 위하여 IPAQ 를 사용하였으며, 이는 국민건강영양조사와 한국의료패 널 등의 대규모 역학 연구에서 사용하고 있다. 그러나 주 단위의 신체활동량을 평가하는데 있어서 유용하지만 대 상이 최근 7일로 제한되어 있으므로 신체활동 패턴이 평 상시와 다를 경우, 한 번의 설문조사만으로는 일상 신체 활동량 혹은 에너지 소비량을 평가하기 어렵다는 단점이 있다(20).

Laaksonen et al. [21]은 남성의 경우 4.5METs 이상 주당 1 시간 이하 집단보다 3 시간 이상 운동집 단이 대사증후군 의 위험률이 $48 \%$ 낮게 나타났으며, 60 분 이상의 고강도 운 동 집단의 대사증후군의 위험률이 3 분의 2 가 낮게 나타난 다고 하였다. 신체활동에 참여하는 것은 만성질환 위험인 자를 감소시킬 뿐 아니라 전체 사망 위험률을 감소시킨다 고 보고되고 있다[9]. 본 연구에서도 비활동(inactive) 집단 이 비해 최소활동(minimally active) 집단의 당뇨 유병률의 OR이 0.81(19\% 감소), 고활동(active) 집단의 유병률의 OR 이 $0.73(27 \%$ 감소)로 나타나 신체활동과 당뇨 유병률의 관 계에 대하여 지지하였다 (Table 2). Lee[22]는 신체활동 수 준과 고혈압 유병률을 비교하여 저활동에 비해 최소활동 의 유병률의 $\mathrm{OR}$ 이 0.89 , 고활동의 유병률이 0.77 이라고 하 여 본 연구와 유사한 결과를 보고하였다.

중년 여성의 신체활동 강도에 따른 외래 의료이용차 이 분석에서 중증도 신체활동 빈도와 월평균 외래 의료 이용 횟수의 관계를 제외하면 모든 신체활동이 의료비와 의료 이용을 낮춘다고 보고되고 있다 [23]. Wu et al. [24] 은 Medical Expenditure Panel Survey data (2010-2015)를 이 용하여 BMI 25 이상의 당뇨 환자 중 30 분 이상 운동을 주 당 5 회 이상 참여한 운동집단의 총의료비가 비조정의 경 우 비운동집단의 $61.8 \%$ 수준이며 $(\mathrm{p}<.001)$, 사회경제적 및 건강 관련 변수를 조정한 경우 $22 \%$ 적었으며 $(\mathrm{p}<.001)$ 입 원 기간이 $28 \%$ 짧았다고 하였다( $\mathrm{p}<.01)$. 한국 노인의 신체 활동 정도와 의료이용 측면에서 비활동 집단과 활동 집단 을 비교하면 입 원이용 가능성이 0.54 배, 약국이용은 0.75 배 로 낮았으며, 의료이용횟수도 감소하는 것으로 나타났고, 최소활동 집단을 비활동 집단과 비활동을 비교하여 입원
의료이용 가능성이 0.64 배로 낮고, 이용횟수도 감소하였 다고 하였다 [25]. Sari [18]는 Canadian Community Health Survey를 이용하여 비활동인 경우 입원의료 이용 횟수가 $38 \%$ 증가하며, 주치의를 5.5\% 더 방문하고, 특별 서비스를 $13 \%$ 더 이용한다고 하였다. 본 연구에서도 연간 입원일수 가 고활동 집단의 $9.1 \pm 10.4$ 일에서 최소활동과 비활동 집 단은 $10.1 \pm 15.2$ 일과 $13.7 \pm 22.8$ 일로 $11.0 \sim 50.6 \%$ 가 증가하여 신체활동과 입원 의료이용을 감소의 관계를 지지하고 있 다 (Table 3). 신체활동과 의료이용의 관계성을 보고한 연 구에서도 중간 정도의 신체활동을 하는 사람이 신체활동 을 거의 하지 않는 사람에 비해 외래 의료이용 빈도가 $12 \%$ 낮고 입 원 이용 빈도가 $30 \%$ 낮은 것으로 나타났다 [26].

본 연구에서 활동 집단의 의료비를 살펴보면 연간 개 인의료비I이 $961,462 \pm 1,828,570(\$ 874.1 \pm 1662.3)$ 이고, 교 통비 등이 포함된 연간 개인의료비II가 $\$ 974,406 \pm 1,832$, $655(\$ 885.8 \pm 1,666.1)$ 이었다. 활동 집단의 의료비와 비교해 보면, 최소활동 집단의 의료비가 33.3 35.1\% 많았고, 비 활동 집단은 58.8 65.6\% 정도 많이 지출되었다. 즉, 비활 동 집단에서 더 급격하게 의료비가 증가하는 것으로 나 타났다 (Table 3). Oh [27]는 2009년 한국의료패널 자료를 바탕으로 하여 운동을 하지 않는 사람의 연간 의료비는 \#49,965이고 걷기 운동을 꾸준히 한 사람은 \$518,374으 로 1.64 배 정도 차이가 난다고 하였다. 당뇨 환자를 대상 으로 한 본 연구와 전체 성인을 대상으로 한 $\mathrm{Oh}[27]$ 의 연 간 의료비를 비교해 보면 당뇨 환자의 의료비가 전체 성인 의료비보다 비활동 집단은 $677,147(80.0 \%)$, 최소활동 집 단은 $\$ 762,862(147.2) \%$ 정도 높게 나타났다. Lee[22]이 보 고한 고혈압 환자의 의료비와 본 연구의 당뇨 환자의 의 료비를 비교해 보면, 활동 집단은 $\$ 967,780$ 과 961,462 으로 유사하였으나, 최소활동 집단의 경우 $1,007,515$ 과 \#1,281,23으로 당뇨 환자가 \#273,721(27.2\%) 높았고, 비 활동 집단의 경우 $1,278,095$ 과 $1,527,112$ 으로 당뇨 환 자가 249,017 (19.5\%) 높게 나타났다. Pratt(28)은 미국 성 인 중 규칙적 신체활동 집단의 연간 의료비용은 $\$ 1,019$ 이 며, 비활동 집단의 연간 의료비는 $\$ 1,349$ 이며 $32.4 \%$ 정도 높았다고 하였다. Min [29]은 한국 건강보험공단의 68,556 명의 자료를 신체활동에 따라 고저로 양분하여 의료비용 을 분석하고 저활동 집단이 고활동 집단보다 $11.7 \%$ 높았 으며 $\$ 1,110.5$ 였다고 하였다. 국가간의 보험 체계와 해당 시기 및 집단 선정 기준이 차이가 있어 직접적인 비교에 한계가 있지만 신체활동 집단의 연간 의료비는 미국 [28] 
이 한국 [27] 보다 $\$ 547$, 비활동 집단의 의료비는 \$576가 더 많게 나타났다. Peeters [30]는 호주 중년 여성을 대상으로 하여 고활동 집단의 연간 의료비는 $\$ 506$ 이고, 비활동 집 단의 의료비는 $\$ 544$ 라고 하여 신체활동 수준에 따라 유의 한 차이가 나타났으나 좌식 생활 시간에 따른 차이는 나 타나지 않았다고 하였다. 이를 한국 [27]의 의료비와 비교 해 보면, 비활동 집단은 한국이 $\$ 70$ 적으나, 고활동 집단 은 호주가 $\$ 179$ 정도 높은 수준이었다. 본 연구와 많은 연 구들에서 의료비는 환자가 의료기관에 지불한 수납금액 이나 민간보험과 건강보험 부담액 등을 총의료비 차원에 서도 추가적으로 조사하면 더욱 의미 있는 결과가 도출 될 것으로 기대된다.

당뇨 환자를 대상으로 한 본 연구와 Lee [22]의 고혈압 환자 비율을 비교해 보면 비활동 집 단이 $46.8 \%$ 와 $54.2 \%$ 이 고, 최소활동 집단이 $44.7 \%$ 와 $39.2 \%$, 활동 집 단이 $8.5 \%$ 와 $6.6 \%$ 로 나타났다. 비활동 집단은 고혈압 환자의 비율이 $7.4 \%$ 높았으나 최소활동 집단은 당뇨 환자의 비율이 $5.5 \%$ 높았고 활동 집단은 당뇨 환자의 비율이 $1.9 \%$ 높게 나타 났으며, 이 연구들은 신체활동 수준과 고협압과 당뇨 환 자의 발현에 의미 있는 결과를 지지하였다. 향후에는 비 활동 집단의 대상자의 신체활동을 증가시켜 최소활동 집 단의 비율을 증가시키면 연간 의료비, 입원일수, 입원 및 응급실 이용 등의 비율을 감소시켜 의료비와 의료이용 감 소에 긍정적인 작용을 하리라 기대된다.

\section{결론}

당뇨 유병률은 비활동 집단에 비해 최소활동 집단의 $\mathrm{OR}$ 이 0.81 , 고활동 집단이 $0.73(\mathrm{p}<.01)$ 으로 감소하였고, $\mathrm{BMI}$, 흡연과 음주 변수를 공변량으로 하고 최소활동 집 단의 $\mathrm{OR}$ 이 0.82 , 고활동 집단의 $\mathrm{OR}$ 이 $0.76(\mathrm{p}<.01)$ 로 감소 하는 것으로 나타났다. 당뇨 환자의 신체활동 집단에 따 른 연간 개인의료비 $\mathrm{I}(\mathrm{p}<.05)$ 과 $\mathrm{II}(\mathrm{p}<.01)$ 는 모두 신체활동 집단간에 유의한 차이가 나타났다. 고활동 집단을 기준 으로 의료비를 비교해 보면 최소활동 집단은 33.3 35.1\% 증가하였으나 비활동 집 단은 $58.8 \sim 65.6 \%$ 증가하여 비활 동 집단에서 급격하게 증가하였다. 신체활동 수준에 따 른 입원과 응급 이용 여부에는 유의한 차이가 나타났으 며 $(\mathrm{p}<.01)$, 신체활동이 입원과 응급 이용 비율 감소에 긍 정적인 작용을 하는 것으로 나타났다. 그러나 외래 여부 에는 유의한 차이가 나타나지 않았다. 당뇨 유병률은 비
활동 집단보다 최소활동 집단과 고활동 집단 순으로 더 감소하였고 당뇨 환자는 신체활동이 감소할수록 의료비 용이 증가하였으며, 입원과 응급 이용에 긍정적인 작용을 하는 것으로 나타났다.

\section{Acknowledgments}

본 논문은 2018년 상명 대학교 교내선발과제 연구비의 지원을 받아 연구되었음

\section{Conflicts of Interest}

The authors declare no conflict of interest.

\section{References}

1. Warburton DE, Nicol CW, Bredin SS. Health benefits of physical activity: the evidence. CMAJ. 2006 14;174(6):801-9.

2. Lee I, Shiroma EJ, Lobelo F, Puska P, Blair SN, Katzmarzyk $\mathrm{PT}$, et al. Effect of physical inactivity on major noncommunicable diseases worldwide: an analysis of burden of disease and life expectancy. The lancet. 2012;380(9838):219-29.

3. World Health Organization. Global recommendations on physical activity for health. 2010.

4. WHO : Physical activity Key facts [Internet]. [cited 03 September 2018]. Available from: http://www.who.int/ en/news-room/fact-sheets/detail/physical-activity.

5. Centers for Disease Control and Prevention. National diabetes statistics report: estimates of diabetes and its burden in the United States, 2014. Atlanta, GA: US Department of Health and Human Services. 2014;2014.

6. Heron M. Deaths: leading causes for 2010. Natl Vital Statistics Rep. 2013;60(6):1-96.

7. Ministry of Health and Welfare of Korea. Korea National Health and Nutrition Examination Survey (2017). 2018.

8. Boyle JP, Thompson TJ, Gregg EW, Barker LE, Williamson DF. Projection of the year 2050 burden of diabetes in the US adult population: dynamic modeling of incidence, mortality, and prediabetes prevalence. Population Health Metrics. 2010;8(1):29. 
9. American College of Sports Medicine. ACSM's resource manual for guidelines for exercise testing and prescription. Wolters Kluwer: Lippincott Williams \& Wilkins; 2012, p 2-15.

10. Moraes MR, Bacurau RF, Casarini DE, Jara ZP, Ronchi FA, Almeida SS, et al. Chronic conventional resistance exercise reduces blood pressure in stage 1 hypertensive men. J Strength Cond Res. 2012; 26(4):1122-9.

11. Dutton GR, Lewis CE. The Look AHEAD Trial: implications for lifestyle intervention in type 2 diabetes mellitus. Prog Cardiovasc Dis. 2015;58(1):69-75.

12. Look AHEAD Research Group, Wing RR. Long-term effects of a lifestyle intervention on weight and cardiovascular risk factors in individuals with type 2 diabetes mellitus: four-year results of the Look AHEAD trial. Arch Intern Med. 2010;170(17):1566-75.

13. Look AHEAD Research Group. Cardiovascular effects of intensive lifestyle intervention in type 2 diabetes. $\mathrm{N}$ Engl J Med. 2013;369(2):145-54.

14. Boulé NG, Haddad E, Kenny GP, Wells GA, Sigal RJ. Effects of exercise on glycemic control and body mass in type 2 diabetes mellitus: a meta-analysis of controlled clinical trials. JAMA. 2001;286(10):1218-27.

15. Cornelissen VA, Smart NA. Exercise training for blood pressure: a systematic review and meta-analysis. Journal of the American Heart Association. 2013;2(1):e004473.

16. Woolcott JC, Ashe MC, Miller WC, Shi P, Marra CA, PACC Research Team. Does physical activity reduce seniors' need for healthcare?: a study of 24281 Canadians. Br J Sports Med. 2010;44(12):902-4.

17. Lee JA. Relationship between Grip Strength and Prevalence of Hypertension in Korean Adults: the Sixth Korea National Health and Nutrition Examination Survey (2015). J Kinesiology. 2017;19(3):53-60.

18. Sari N. Physical inactivity and its impact on healthcare utilization. Health Econ. 2009;18(8):885-901.

19. Craig CL, Marshall AL, Sjostrom M, et al. International physical activity questionnaire: 12-country reliability and validity. Med Sci Sports Exerc. 2003;35(8):1381-95.

20. Yang YJ, Yoon YS, Lee ES, et al. Development of selfadministered questionnaire for the assessment of physical acitivity. Kor J Health Prom. 2005;5(3):178-98. 21. Laaksonen DE, Lakka HM, Salonen JT, Niskanen LK, Rauramaa R, Lakka TA. Low levels of leisure-time physical activity and cardiorespiratory fitness predict development of the metabolic syndrome. Diabetes Care. 2002;25(9):1612-8.

22. Lee BK. Comparison of Prevalence of Hypertension and Medical Expenses According to the Level of Physical Activity of Korean Adults. The Asian Journal of Kinesiology. 2018;20(4):43-9.

23. Cho YS. Differences in outpatients healthcare utilization by level of physical activity among middle-aged Korean women [dissertation]. Seoul National University Thesis; 2015.

24. Wu J, Davis-Ajami ML, Lu ZK. Real-world impact of ongoing regular exercise in overweight and obese US adults with diabetes on health care utilization and expenses. Primary care diabetes. 2019; article in press.

25. Kwak Kl, Baek CH, Ryu SY. Relationship between the physical activity levels and health care utilization in korean elderly. J Kor Acad Indust Cooper Soc. 2015;16(1):617-26.

26. Sevick MA, Dunn AL, Morrow MS, Marcus BH, Chen GJ, Blair SN. Cost-effectiveness of lifestyle and structured exercise interventions in sedentary adults: results of project ACTIVE. Am J Prev Med. 2000;19(1):1-8.

27. Oh YH. An Econometric Analysis of the Difference between Exercisers and Non-Exercisers in medical Care Use. Health and Social Welfare Rev. 2013;33(4):471-96.

28. Pratt M, Macera CA, Wang G. Higher direct medical costs associated with physical inactivity. The Physician and Sportsmedicine. 2000;28(10):63-70.

29. Min J, Min K. Excess medical care costs associated with physical inactivity among korean adults: retrospective cohort study. International Journal of Environmental Research and Public Health. 2016;13(1):136.

30. Peeters GG, Mishra GD, Dobson AJ, Brown WJ. Health care costs associated with prolonged sitting and inactivity. Am J Prev Med. 2014;46(3):265-72. 